\title{
COMPORTAMIENTO DE UNA SELECCIÓN DE EMISORES PARA FERTIRRIEGO DE CULTIVOS HORTÍCOLAS EN INVERNADERO CON AGUAS REGENERADAS
}

\author{
Baeza Cano, R., Contreras París, J.I., Trujillo Delgado, J., Alonso López, F.
}

Instituto de Investigación y Formación Agraria y Pesquera de Andalucía (IFAPA), Centro La Mojonera, Camino San Nicolás, n¹, 04745 La Mojonera, Almería.

rafaelj.baeza@juntadeandalucia.es

\section{Resumen}

Las Aguas Residuales Urbanas Regeneradas (ARUR) se muestran como una fuente alternativa de agua para riego en áreas con recursos tradicionales deficitarios, tal es el caso de las zonas costeras de Andalucía. Estas aguas, en general, se caracterizan por presentar una peor calidad física y biológica que las tradicionales aguas subterráneas, con niveles relativamente altos de sólidos en suspensión y elevada presencia bacteriana. Como consecuencia de esto se incrementan los fenómenos de obturación de los emisores de riego En pro de obtener información del tipo de emisores que mejor se adaptan a este tipo de agua, el IFAPA ha instalado un banco de ensayo en condiciones de campo, en el que, utilizando aguas regeneradas se seleccionaron, en un ensayo previo, 20 modelos de emisores que se han sometido a tres tratamientos: T1: riego con agua residual urbana regenerada; T2: fertirriego con agua residual urbana regenerada + equilibrio fertilizante estándar y T3: fertirriego con agua residual urbana regenerada + equilibrio fertilizante estándar + mantenimiento. Los resultados de la primera campaña de riego muestran una elevada uniformidad de distribución de caudal en todos los emisores seleccionados, si bien se aprecian diferencias significativas entre ellos. Se han detectado pequeños porcentajes de reducción de caudal en el $30 \%$ de los modelos de emisores. En esta primera campaña aún no se observan diferencias entre tratamientos.

\section{1- Introducción y objetivos}

Los cultivos hortícolas bajo invernadero desarrollados en el Sureste de España acaban de cumplir 50 años de trayectoria. A lo largo de esta media década de desarrollo se han producido numerosos cambios en el sistema. La mayor parte de ellos propiciados por la natural evolución de la tecnología. En ocasiones las evoluciones han sido necesarias adaptaciones a problemas surgidos. Tal es el caso de la disponibilidad de recursos hídricos que, tras la disminución de las reservas de aguas subterráneas o, el empeoramiento de su calidad, por fenómenos como la intrusión marina, ha obligado a la incorporación de nuevas fuentes de agua como las Residuales Urbanas Regeneradas (ARUR) o las procedentes de cursos fluviales. Estas aguas en general se caracterizan por presentar una buena calidad química, pero, sin embargo una peor calidad física y biológica que las tradicionales aguas subterráneas, con niveles relativamente altos de sólidos en suspensión y elevada presencia bacteriana. Como consecuencia de esto se han detectado problemas relacionados con el mantenimiento de las instalaciones de riego, las cuales pueden verse afectadas por la calidad específica de estos efluentes, especialmente en lo que se refiere a la obturación de emisores en los sistemas de riego localizado. Niveles de sólidos en suspensión superiores a $78 \mathrm{mg} \mathrm{L}^{-1}$ no permiten una uniformidad óptima en el riego (Capra et al. 2004). 
Afortunadamente, las aguas regeneradas presentan valores en este parámetro muy inferiores. Estudios realizados durante varias campañas por el IFAPA en La Cañada (Almería) muestran valores medios en finca de $8,33 \mathrm{mg} \mathrm{L}^{-1}$, con máximos que en ningún caso superan los $10 \mathrm{mg} \mathrm{L}^{-1}$ (Contreras, 2014). Sin embargo, los principales agentes obturadores no son exclusivamente los sólidos en suspensión, sino la aglomeración de éstos (partículas finas minerales u orgánicas) con subproductos microbianos y biomasa desarrollada en el interior de las tuberías y ramales (Ravina et al. 1992). Este aspecto (desarrollo de biomasa) hace que sea tanto o más importante un adecuado diseño y mantenimiento de la red de riego que la calidad del agua de partida. Estudios prospectivos previos desarrollados en campo demuestran que las instalaciones de riego en las fincas que utilizan estas aguas presentan habitualmente problemas de funcionamiento y uniformidad relacionados con frecuencia a obturaciones en los emisores (Baeza et al. 2010). En pro de obtener información del tipo de emisores que mejor se adaptan a las nuevas condiciones, el IFAPA, en colaboración con las empresas fabricantes e instaladoras, puso en marcha un ensayo de evaluación de 38 modelos de emisores en condiciones de campo. Tras analizar los resultados obtenidos en dos campañas de evaluación se realizó una selección de 20 modelos a los que se les está realizando un seguimiento en diferentes condiciones de trabajo.

\section{2- Materiales y métodos}

El ensayo se ha desarrollado en un invernadero experimental multitúnel de $1200 \mathrm{~m}^{2}$, situado en las instalaciones que posee el Centro IFAPA La Mojonera en La Cañada (Almería) y equipado con control automático de clima y de riego. Este invernadero dispone de un banco de pruebas de emisores, preparado para evaluar 240 líneas de riego. Se estableció un diseño experimental factorial con dos factores, tipo de emisor y manejo del riego, con tres repeticiones en bloques al azar, donde la unidad experimental básica ha sido el lateral de riego (Figura 1). Los tipos de emisores evaluados fueron 20 modelos comerciales de goteros seleccionados en estudios previos (Contreras et al. 2013) (Tabla 1).

Tabla 1. Selección de emisores evaluados

\begin{tabular}{|c|l|l|l|c|}
\hline & MODELO & FABRICANTE & $\begin{array}{l}\text { TIPO DE } \\
\text { INSERCIÓN }\end{array}$ & $\begin{array}{c}\text { COMPENSACIÓN } \\
\text { DE CAUDAL }\end{array}$ \\
\hline 1 & T D Advanced OL & MONDRAGON & pinchado & NO \\
\hline 2 & ADO & CAUDAL & pinchado & SI \\
\hline 3 & Interlinea 12 & HIDROTEN & interlinea & NO \\
\hline 4 & NYA & PRIMARAM & Interlinea & NO \\
\hline 5 & PCJ & NETAFIN & pinchado & SI \\
\hline 6 & Conico desmontable & HIDROTEN & pinchado & NO \\
\hline 7 & PC-CNL & NETAFIN & pinchado & SI \\
\hline 8 & TD Advanced M & MONDRAGON & pinchado & NO \\
\hline 9 & Hydrogol & JOHN DEERE WATER & integrado & NO \\
\hline 10 & AGR & AZUD & Interlinea & NO \\
\hline 11 & AmnonDrip & NAANDANJAIN Iberica & integrado & SI \\
\hline 12 & Interlinea 16 & HIDROTEN & interlinea & NO \\
\hline 13 & Interlinea 16 & AMACOM & Interlinea & NO \\
\hline 14 & PRO & AZUD & Integrado & NO \\
\hline 15 & Megadrip & MONDRAGON & Integrado & SI \\
\hline 16 & Topdrip & NAANDANJAIN Iberica & integrado & SI \\
\hline 17 & Hydro PC & JOHN DEERE WATER & Integrado & SI \\
\hline 18 & Unirran & NETAFIN & Integrado & SI \\
\hline 19 & LIN & Extruline Caudal & Integrado & NO \\
\hline 20 & ARIES & NETAFIN & Integrado & NO \\
\hline
\end{tabular}


En el invernadero de pruebas, los emisores se sometieron a pulsos continuos de riego de 30 minutos, realizando 5 aplicaciones semanales durante un periodo de 20 semanas, con un gasto aproximado de agua de $150 \mathrm{~L}^{\text {emisor }}{ }^{-1}$, equivalente a una campaña de riego en un ciclo medio de cultivos hortícolas en invernadero. El agua utilizada ha sido agua residual urbana procedente de la ciudad de Almería y regenerada mediante tratamiento terciario de filtración, ozonización y/o cloración.

En lo que respecta al manejo de riego se dispusieron tres tratamientos:

T1-Riego con agua residual urbana regenerada.

T2-Fertirriego con agua residual urbana regenerada+equilibrio fertilizante estándar.

T3-Fertirriego con agua residual urbana regenerada+equilibrio fertilizante estándar+mantenimiento.

El equilibrio fertilizante estándar consistió en una solución nutritiva media para el cultivo de tomate bajo abrigo.

Las labores de mantenimiento practicadas al tratamiento T3 fueron:

- $\quad$ Apertura durante varios segundos de los tapones finales de los ramales de riego para la limpieza de los sedimentos. Esta labor se realizaba con una periodicidad mensual.

- $\quad$ Mantenimiento del $\mathrm{pH}$ de la solución de riego en valor constante de $\mathrm{pH} 6$ para evitar la formación de precipitados.

A los tratamientos T1 y T2 no se les realizó labor alguna de mantenimiento.
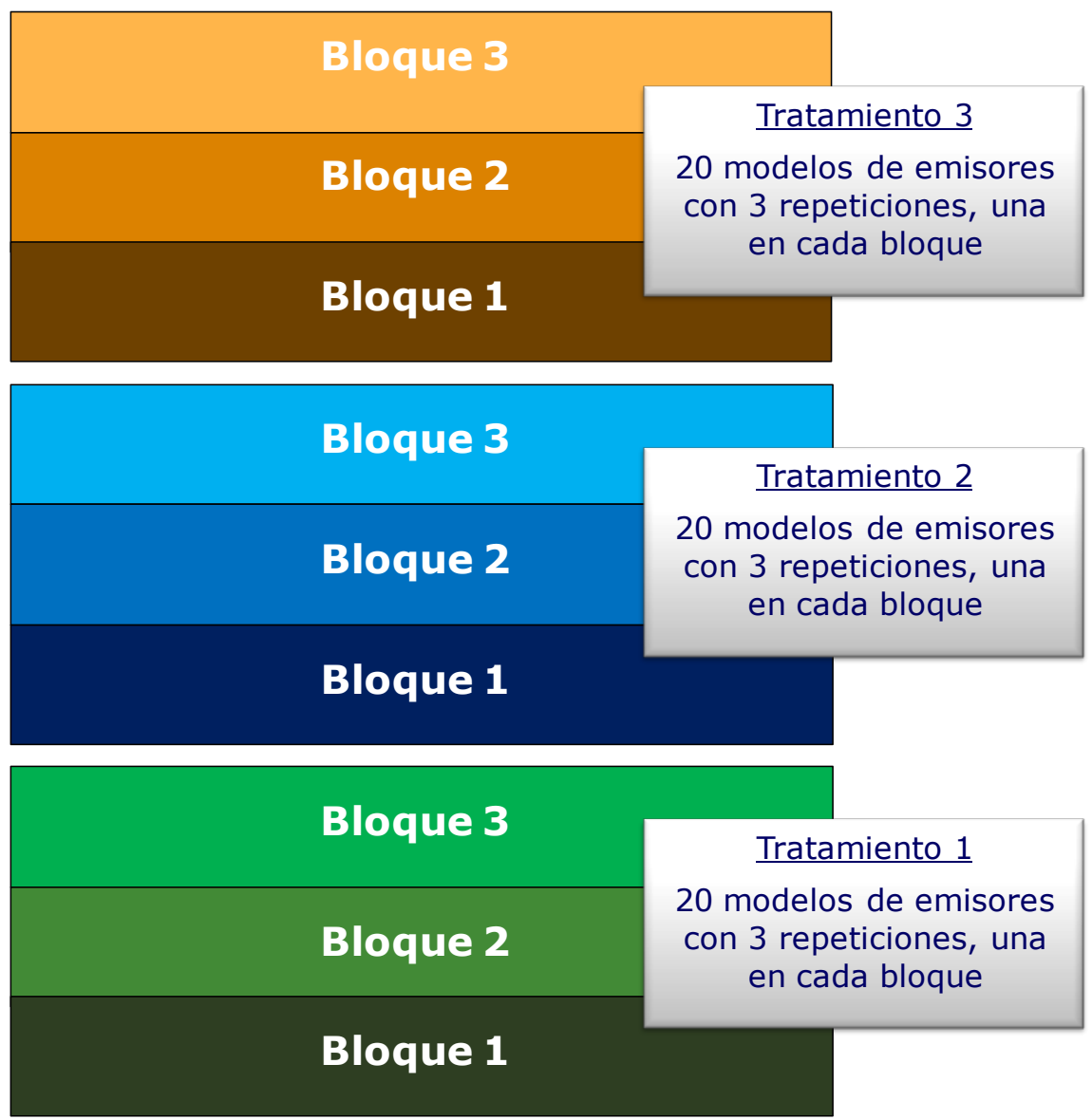

Figura 1. Diseño experimental del ensayo. 
El ensayo está dividido en 3 sectores de riego, cada uno de los cuales corresponde a un tratamiento. El sector cuenta con 60 laterales de riego, una válvula de regulación a la entrada y 5 manómetros de control distribuidos a lo largo de la tubería portalaterales (Figura 2). Tanto en las aplicaciones de riego como en las evaluaciones se ha mantenido una altura manométrica constante de 1,5 bar. La longitud de los laterales es de $16 \mathrm{~m}$, equivalentes a 31 emisores.

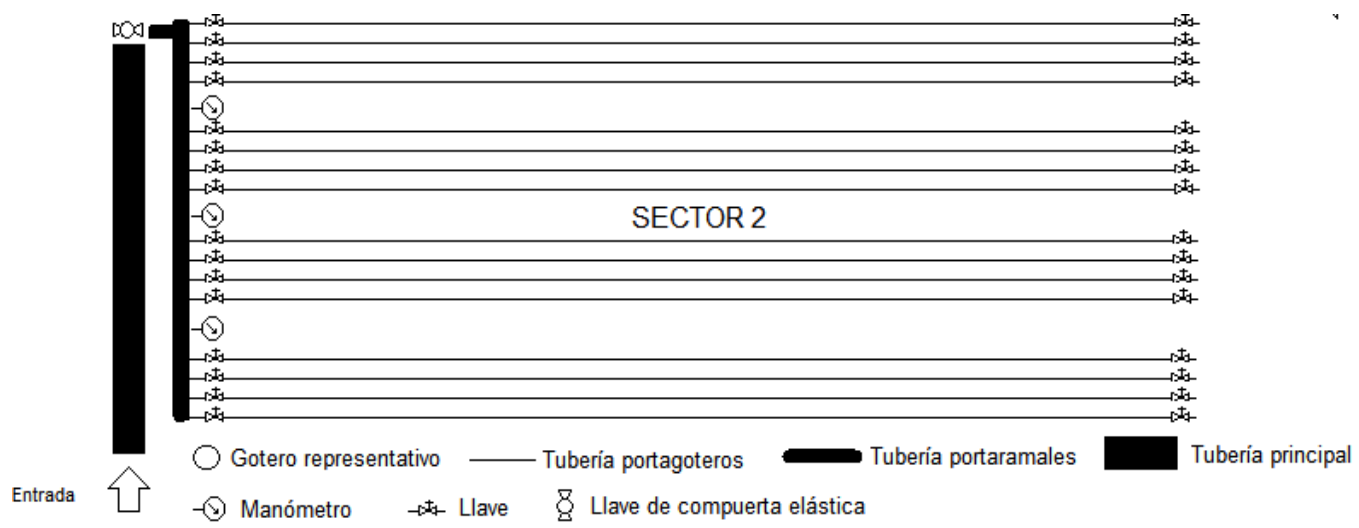

Figura 2. Esquema de un sector de la red de evaluación. En cada lateral de 31 emisores se han medido 16 emisores representativos.

El invernadero se equipó con un sistema de drenaje que permitió la evacuación del agua aplicada. El agua utilizada ha sido suministrada por la Comunidad de Regantes Las Cuatro Vegas, responsable de la regeneración y distribución de las aguas residuales urbanas regeneradas de la ciudad de Almería.

Se realizó una evaluación de caudales inicial (antes de comenzar la campaña de riego) y otra final, así como evaluaciones intermedias mensuales. La toma de datos se ha facilitado con el uso de cuatro carros de muestreo, con una capacidad individual de 16 mediciones de volumen (Foto 1). Se determinó el coeficiente de uniformidad de caudales y el porcentaje de reducción de caudal, como indicador de la obturación.

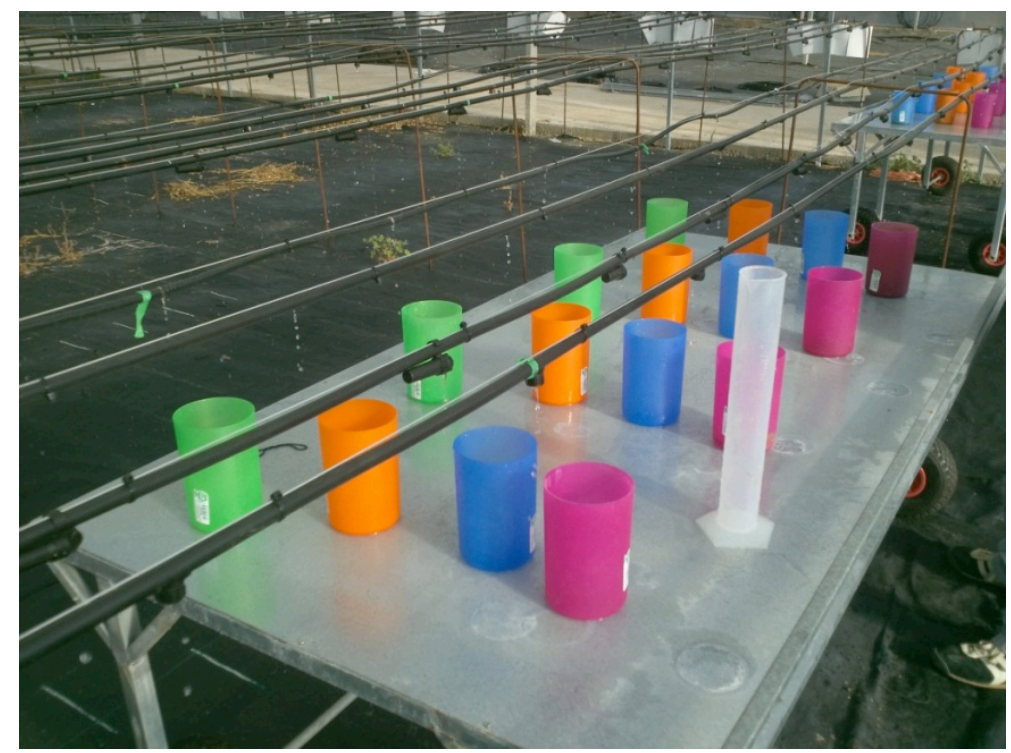

Foto 1. Carro empleado en la toma de muestras. 
El coeficiente de uniformidad de caudales se ha estimado utilizando la metodología clásica planteada por John L. Merriam y Jack Keller en 1978, cuya expresión de cálculo es la siguiente:

$\operatorname{CUC}=\left(\mathrm{q}_{25 \%} / \mathrm{q}_{\mathrm{m}}\right)^{*} 100$

\begin{tabular}{|cc|}
\hline CUC & Calificación \\
\hline$>\mathbf{9 5 \%}$ & Excelente \\
\hline $\mathbf{8 5 \% - 9 5 \%}$ & Buena \\
\hline $\mathbf{8 0 \% - 8 5 \%}$ & Aceptable \\
\hline $\mathbf{7 0 \% - 8 0 \%}$ & Pobre \\
\hline$<\mathbf{7 0 \%}$ & Inaceptable \\
\hline
\end{tabular}

CUC $=$ Coeficiente de Uniformidad de Caudal, en tanto por 100.

$\mathrm{q}_{25 \%}=$ Promedio de los caudales del $25 \%$ de los emisores, cuyo caudal sea de menor valor.

$\mathrm{q}_{\mathrm{m}}=$ Promedio del caudal del total de los emisores.

Los resultados han sido analizados estadísticamente con el software STATGRAPHICS Plus (versión 5.1). Se realizó un análisis multifactorial ANOVA para identificar la significación de los factores estudiados. Cuando el análisis estadístico reveló diferencias significativas entre tratamientos se aplicó un test de comparación de media (LSD; mínima diferencia significativa) con $p \leqslant 0.05$.

\section{3.- Resultados y conclusiones}

Los emisores estudiados han obtenido un coeficiente inicial de uniformidad de caudal superior al $90 \%$ en todos los modelos, siendo en 17 de los 20 modelos superior al 95\%. Estos valores corroboran la buena calidad del material de partida (Figura 3).

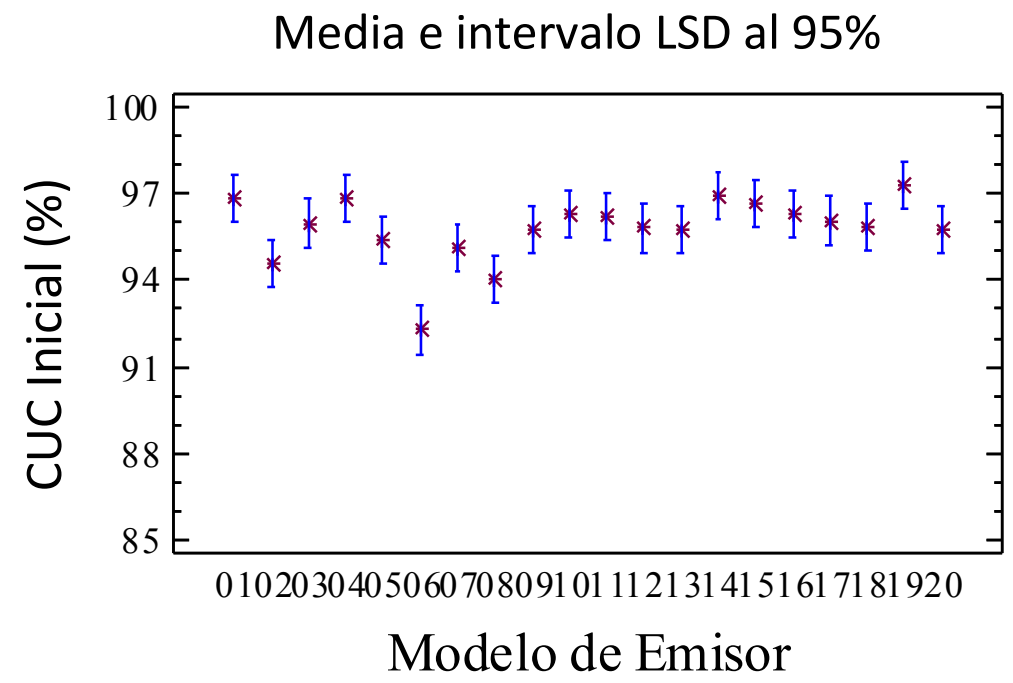

Figura 3. Coeficiente de Uniformidad de Caudal (CUC) inicial, en tanto por cien, para los 20 modelos analizados. Se ha representado el intervalo de Mínima Diferencia Significativa (LSD) al $95 \%$. 
Tabla 2. Nivel de significación de los factores estudiados e interacciones entre factores.

\begin{tabular}{lccc}
\hline & CUC Inicial (\%) & CUC Final (\%) & $\%$ Reducción caudal \\
\hline Factor & & & \\
A: Tratamiento & ns & ns & ns \\
B: Modelo Emisor & $* *$ & & \\
Interacción & & & $n$ \\
AB & ns & ns & ns \\
\hline
\end{tabular}

ns, no significativo.

*Significativo para $P<0.05$.

**Significativo para $P<0.001$.

Tras la primera campaña de riego, el modelo de emisor ha influido significativamente en la respuesta a la uniformidad de caudal (Tabla 2). Únicamente 6 de los 20 emisores mantienen una uniformidad superior al $95 \%$. No obstante sólo en uno de los modelos se ha determinado una uniformidad inferior al $90 \%$ (Figura 4). Al avanzar la campaña ha aumentado la dispersión de los valores de uniformidad, pudiéndose afirmar por tanto que se está produciendo efecto en los emisores (Figuras 3 y 4). Sin embargo este efecto no ha permitido aún observar diferencias significativas entre tratamientos (Tabla 2). Será necesario someter a los emisores a varias campañas de riego para poder sacar conclusiones a este respecto.

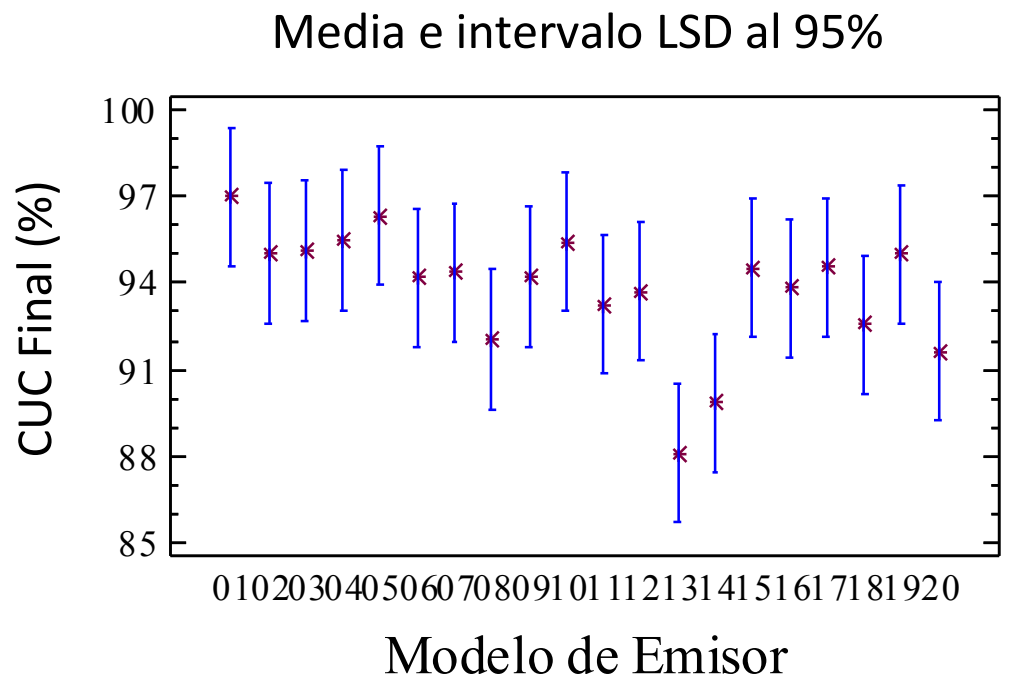

Figura 4. Coeficiente de Uniformidad de Caudal (CUC) final, en tanto por cien, obtenido en la primera campaña para los 20 modelos analizados. Se ha representado el intervalo de Mínima Diferencia Significativa (LSD) al 95\%.

En esta primera campaña de riego los porcentajes de obturación sufridos por los emisores son bajos. Sólo en tres de los modelos evaluados el porcentaje de obturación es superior al $4 \%$. Este es un fenómeno que con déficit de mantenimiento va incrementándose al aumentar el trabajo del emisor. Es difícil, con una única campaña de riego, dilucidar que 
modelos tienen un mejor comportamiento en este aspecto. Previsiblemente se obtendrán conclusiones definitivas al respecto en las próximas campañas de riego (Figura 5).

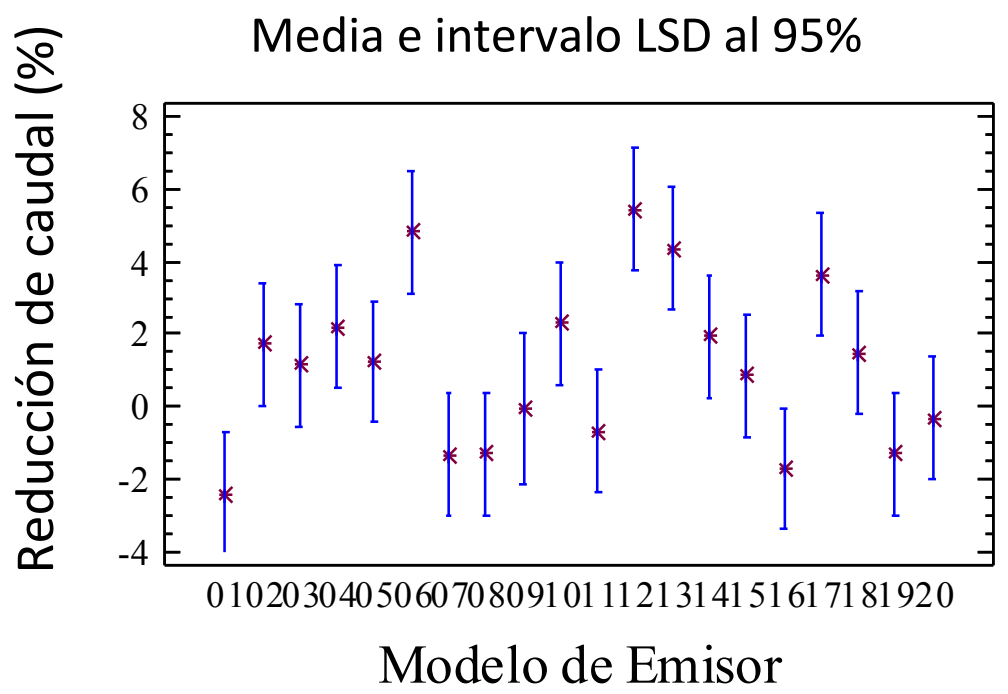

Figura 5. Porcentaje de reducción de caudal con respecto al caudal inicial (obturación) en función del modelo de emisor. Se ha representado el intervalo de Mínima Diferencia Significativa (LSD) al 95\%.

\section{4.-Agradecimientos}

El trabajo ha sido cofinanciado por Fondos Europeos (FSE y FEDER) y la Consejería de Agricultura y Pesca (IFAPA Junta de Andalucía) mediante el Proyecto Transforma Conecta SAR (PP.TRA.TRA201300.10).

\section{5.- Bibliografía}

Baeza Cano, R., Gavilán Zafra, P., Del Castillo Lupiáñez, N., Berenguel, P., López Segura, J.G. 2010. Programa de evaluación y asesoramiento en instalaciones de riego en invernadero con uso de dos fuentes distintas de agua: subterránea y regenerada. XXVIII Congreso Nacional de Riegos. León 15-17 Junio de 2010.

Capra, A., Scicolone, B. 2004. Emitter and filter test for wastewater reuse by drip irrigation. Agricultural Water Management 68: 135-149.

Contreras Paris, J.I. 2014. Optimización de las estrategias de fertirrigación de cultivos hortícolas en invernadero utilizando aguas de baja calidad (agua salina y agua regenerada) en condiciones del litoral de Andalucía. Tesis Doctoral. Universidad de Almería.

Contreras París, J.I., Baeza Cano, R., López Segura, J.G., Gavilán Zafra, P. 2012. Comportamiento de emisores de riego localizado de bajo caudal con aguas residuales urbanas regeneradas. XXX Congreso Nacional de Riegos. 12-14 Junio de 2012.

Merrian, J.L. Keller, J. 1978. Farm irrigation system evaluation: a guide for management. Utah State University.

Ravina, I., Paz, E., Sofer, Z., Marcu, A., Shisha, A., Sagi, G. 1992. Control of emitter clogging in drip irrigatión with reclaimed wastewater. Irrigatión Science 13:129-139. 